\title{
Comprehensive pregnancy knowledge level among out-of-school youths in Wayu Tuka district, Western Ethiopia
}

\author{
Gemechu Kejela*, Kababa Temesgen \\ ${ }^{1}$ College of Health Sciences, Department of Public Health, Arba Minch University, Arbaminch, Ethiopia \\ ${ }^{2}$ College of Health Sciences, Department of Midwifery, Arba Minch University, Arba Minch, Ethiopia
}

Email address:

gemechukejela86@gmail.com (G. Kejela), Kabetemesgen@gmail.com (K. Temesgen)

\section{To cite this article:}

Gemechu Kejela, Kababa Temesgen. Comprehensive Pregnancy Knowledge Level among Out-of-School Youths in Wayu Tuka District, Western Ethiopia. Science Journal of Public Health. Vol. 3, No. 1, 2015, pp. 75-80. doi: 10.11648/j.sjph.20150301.23

\begin{abstract}
Background: Although there is a high awareness about pregnancy prevention methods among youth, in Ethiopia, the problems are still rampant which indicates lack of comprehensive knowledge about pregnancy among youths. So, having indepth and comprehensive knowledge about pregnancy and associated factors has a paramount importance. Objectives: the main aim of this study is to assess comprehensive pregnancy knowledge level and associated factors among out of school youths in Wayu Tuka district of east Wollega zone. Methods: A quantitative community based cross-sectional study design was used. Data were collected using structured questionnaire from a total of 625 respondents selected systematically from 6 randomly selected kebeles of the district. Data was entered using EPI data version 3.02 and analysed by using SPSS version 16.0. To ascertain the association between dependent and independent variables, binary logistic regression was performed and variables with p-value of less than or equal to 0.3 at binary were entered into multivariable logistic regression analysis. Variables with $\mathrm{p}$-value of $<0.05$ at multivariable regression were considered as statistically significant. Finally, the result was summarized using text and tables. Result: The proportion of comprehensive pregnancy knowledge in this study was $12 \%$. Comprehensive pregnancy knowledge was higher among those who live with their friends/partners (AOR[95\%CI] $=$ $3.1[1.445,6.658]$, who cited health professionals as major pregnancy related information source $(\mathrm{AOR}[95 \% \mathrm{CI}]=3[1.18,4.608])$ and who discuss about sexual matter with their parents or other family members(AOR $[95 \% \mathrm{CI}]=2.58[1.46,4.54])$. Conclusions and Recommendations: In this study, comprehensive pregnancy knowledge was low. So, appropriate information education and communication programs needs to be intensified for out-of-school youths in the study area.
\end{abstract}

Keywords: Out-of-School Youths, Pregnancy, Comprehensive Knowledge, Wayu Tuka

\section{Background}

Youth is the period of transition from early adolescent to adulthood, which comprises individuals between the ages of 15 to 24 years. It is a crucial developmental period characterized by marked physical, emotional, behavioral and intellectual changes (1). Youth cannot be defined as a homogeneous group (2). There is a variation among youths based on their different socio-demographic characteristics (3). Common understanding is that adolescents and youths are free from ill-health and is considered as the healthiest period of person's life due to low mortality rate. However, transition through adolescence and youth period is linked with a number of issues that affect their body, behavior, and social interactions (4).
Behavioral changes that develop during adolescence have a great implication for the health of youths and later adult hood. Majority of young women and men initiate sexual activity during adolescence, and risk for sexually transmitted infections and unwanted pregnancy accompanies this initiation (5).

Early pregnancy is a major health concern because of its association with higher morbidity and mortality for both mother and child. Childbearing during the teenage years frequently has adverse social consequences as well, particularly on educational attainment because women who become mothers in their teens are more likely to curtail their education (6). Globally, 16 million girls aged 15-19 give 
birth every year, and these births occur predominantly in developing countries (1). Teens account for about one-fifth of all unintended pregnancies annually. Twenty six percent of pregnancies among 15-19 year ended in abortion (7). In Ethiopia, teenagers in rural areas and those out of school are much more likely to have started childbearing earlier than their urban counterparts due to lack of pregnancy prevention knowledge (15 and $4 \%$, respectively) (6).

Knowledge about pregnancy is a prerequisite for the prevention and control of the problem. Awareness alone is not enough for the prevention of unwanted pregnancy. In Ethiopia, awareness about pregnancy is high but annually high number of unwanted pregnancies occurs nationwide, that leads to different adverse pregnancy out comes including unsafe abortion (6).

To avert RH problems of young peoples, WHO created a program of action to increase youth's reproductive health awareness and knowledge (1). In addition, Ethiopia developed strategies to increase youth's awareness and knowledge about RH issues (9). Despite all this efforts, youth, in general and out-of-school and rural youths in particular often lack access to RH information and services (10). In addition, In Ethiopia, few studies are conducted among youths on this issue and most of the studies conducted in the country so far are based on in school and urban youths. As a result, there is a shortage of information on vulnerable groups like out of school and rural youths. So, the main aim of this study was to assess comprehensive pregnancy knowledge level and associated factors among out of school youths in communities of Wayu tuka district.

\section{Methods}

\subsection{Study Design and Setup}

A community based cross sectional study was conducted in Wayu Tuka district, East Wollega zone of Oromia regional state, western Ethiopia, from January 13-27, 2014. Wayu Tuka district is one of the 18 districts of East Wollega zone, which is located in the Northern part of the zone at $319 \mathrm{~km}$ away from Addis Ababa. Wayu tuka district is sub-divided in to 10 kebeles for its administrative purposes. According to the 2007 Ethiopian census report, the population of Wayu Tuka district was projected to be 66,194 , out of which, 32,116 were females and 34,078 were males. Youths, (15-24years) accounts for $9,761(15 \%)$ of the total population of the district. Of which 3,938 were females and 5,823 were males (11). Source population of this study was all out of school youths residing in Wayu Tuka district and the study Population were all youths from six randomly selected kebeles found in the district. Outof- school youths who were not currently attending school were included in the study.

\subsection{Sample Size and Sampling Procedures}

Sample size was calculated using single population proportion formula by taking an assumption of proportion of comprehensive pregnancy knowledge of $50 \%$, since the prevalence is unknown from the previous study, 95\% confidence level, $5 \%$ margin of error, design effect of 1.5 and an addition of $10 \%$ non-response rate. The final sample size was computed to be 634 out-of-school youths.

Multistage sampling technique was applied. Procedurally, first by assuming there is a difference in knowledge level between urban and rural youths, all the 10 kebeles in the district were stratified based on their geographical areas as one urban and nine rural kebeles. The urban kebele was taken for comparison purpose and by assuming that rural kebeles are relatively homogenous, five kebeles out of the nine rural kebeles were selected using lottery method. Totally six kebeles were included in the study. Pre-survey was conducted in each selected kebeles to identify households with out of school youths. Thirdly, out of each selected kebeles, households with out of school youths were allocated using PPS. Finally, households with study samples were selected using systematic sampling method. The first house included in the study was selected by lottery method. If there were more than one out of school youths in the same household, one was selected using lottery method. Where there was no respondent (the house was closed), repeated visit up to three times was conducted. In case it was closed after repeated visits, they were documented as nonrespondents.

\subsection{Data Collection Tools}

Structured interviewer administered questionnaire was adopted from EDHS and study conducted on the same topic in different areas and modified based on the study variables and local context. Twelve tenth grade completed data collectors of both sex and two B.Sc. nurse supervisors were recruited and trained. After training, pre-test was done on 5\% of the sample. Then, data was collected by sex matched data collectors to minimize non-response and social desirability bias. To ensure the quality of data, the questionnaire and consent documents were first developed in English, then translated into local language (Afan Oromo), and finally retranslated into English to check its consistency. Training was given for data collectors and supervisors and the questionnaire was pretested on $36(5 \%)$ of samples who live in kebeles which were not selected for the study before the actual data collection. Supervisors and principal investigator were closely monitored the day-to-day data collection process. Finally data were sorted, checked, entered into the computer and cleaned for analysis.

\subsection{Measurements}

The following operational definitions were used: Out of school Youths were defined in this study as youths who are not currently attending school. Comprehensive pregnancy knowledge was also defined as knowledge of the possibility of pregnancy occurrence on first sex, knowledge of pregnancy occurrence dates in relation to menstrual cycle and knowledge of more than one pregnancy prevention methods (condom which is used as a dual protection for unmarried 
young peoples and at least one other pregnancy prevention method).

\subsection{Data Processing and Analysis}

Data were entered into EPI data version 3.02 and exported to SPSS version 16.0 for analysis. Frequencies of different variables were determined and followed by cross tabulations to compare their frequencies. Binary logistic regression was conducted for dependent and independent variables and crude odds ratio (COR) with $95 \%$ confidence interval was estimated to assess the association between dependent and in dependent variables. Then variables with p-value of $\leq 0.3$ at binary logistic regression were taken into multivariable logistic regression analysis to assess their association with comprehensive pregnancy knowledge. Hosmer-lemeshow goodness-of-fit with stepwise (backward elimination) was used to test for model fitness. Adjusted odds ratio (AOR) with $95 \%$ confidence interval was estimated to assess the presence of association at multivariable logistic regression. Variables with p-value of $<0.05$ at multivariable logistic regression were considered as statistically significant predictors of comprehensive pregnancy knowledge. Finally, the analyzed data were summarized using text and tables.

\subsection{Ethical Considerations}

Ethical clearance was obtained from Institutional Health Research Ethics Review Committee of Haramaya University College of Health and medical Sciences. An official letter was written from School of Graduate Studies to Wayu Tuka district administration office. Further written consent was secured from district health office. Also Kebele administrators were communicated through formal letters from district administration office. Signed assent/consent was obtained from parent/guardian and the respondent, for youths between 15-18 age groups and from the respondent only, if he/she was above 18 years, through addressing the necessary explanation about the purpose of the study and its procedure, assurance of confidentiality, privacy and the right to with draw the participation at any time without any consequences. Participants were also assured that, they did not face any problem for their participation in the study.

\section{Results}

\subsection{Socio-Demographic Characteristics of the Respondents}

A total of 634 respondents were included in the study. Of these, 625 of them were responded which resulted in response rate of $98.58 \%$. Males and females constitutes, 389 $(62.2 \%)$ and $236(37.8 \%)$ respectively. The age of the respondents range from 15 to 24 with mean of 20.05 and standard deviation of 2.473. Majority, 448(96.8\%) of respondent's father and almost all, 538 (99.3\%) of the respondent's mother were farmers and house wife respectively (Table 1).
Table. 1. Socio-demographic characteristics among out-of-school youths, Wayu Tuka district, East Wollega zone, Oromia regional state, western Ethiopia, 2014. $(n=625)$

\begin{tabular}{|c|c|c|}
\hline Variables & Number & Percent (\%) \\
\hline \multicolumn{3}{|l|}{ Sex } \\
\hline Male & 389 & 62.2 \\
\hline Female & 236 & 37.8 \\
\hline \multicolumn{3}{|l|}{ Age } \\
\hline $15-19$ & 246 & 39.4 \\
\hline $20-24$ & 379 & 60.6 \\
\hline \multicolumn{3}{|l|}{ Residence } \\
\hline Urban & 90 & 14.4 \\
\hline Rural & 535 & 85.6 \\
\hline \multicolumn{3}{|l|}{ Ethnicity } \\
\hline Oromo & 613 & 98.1 \\
\hline Others & 12 & 1.9 \\
\hline \multicolumn{3}{|l|}{ Marital status } \\
\hline Unmarried & 494 & 79 \\
\hline Married & 131 & 21 \\
\hline \multicolumn{3}{|l|}{ Literacy level } \\
\hline No formal education & 66 & 10.6 \\
\hline Primary & 282 & 45.1 \\
\hline Secondary & 228 & 36.5 \\
\hline 12 and above & 49 & 7.8 \\
\hline \multicolumn{3}{|l|}{ Parent Vital Status } \\
\hline Both alive & 407 & 65.1 \\
\hline Both died & 27 & 4.3 \\
\hline Father alive & 56 & 9 \\
\hline Mother alive & 135 & 21.6 \\
\hline \multicolumn{3}{|l|}{ Living arrangement } \\
\hline With parents & 430 & 68.8 \\
\hline With friends/partners & 164 & 26.2 \\
\hline With relatives/others & 31 & 5 \\
\hline \multicolumn{3}{|l|}{ Father's literacy level } \\
\hline No formal education & 341 & 73.7 \\
\hline Primary & 81 & 17.5 \\
\hline Secondary and above & 41 & 8.9 \\
\hline \multicolumn{3}{|l|}{ Mother's literacy level } \\
\hline No formal education & 460 & 84.9 \\
\hline Primary & 70 & 12.9 \\
\hline Secondary and above & 12 & 2.2 \\
\hline
\end{tabular}

\subsection{Pregnancy Related Knowledge}

Knowledge of pregnancy prevention (contraceptive) methods: Five hundred forty eight $(87.7 \%)$ of respondents know one or more pregnancy prevention methods. Pills were the most commonly known 409 (74.6\%) followed by condom 264 (48.2\%), Dipo 260 (47.4\%), Norplant 157(28.6\%), abstinence $44(8 \%)$ and intrauterine contraceptive device (IUCD) $44(8 \%)$ among youths in the area. Majority of the respondents know both condom and pills 176(28.2\%) followed by condom and Dipo, 128(20.5\%), condom and Norplant 93(14.8\%), condom and IUCD 29(4.6\%) and condom and abstinence $23(3.7 \%)$.

The major sources of information for pregnancy prevention methods indicates that, $87(15.9 \%)$ of respondents cited family members, $87(15.9 \%)$ cited friends/partners, $325(59.3 \%)$ cited media and $49(8.9 \%)$ cited health professionals as their major sources of information. 
Table 2. Comprehensive Pregnancy knowledge level among out-of-school youths, Wayu Tuka district, East Wollega Zone, Oromia Regional State, 2014. $(n=625)$

\begin{tabular}{lcc}
\hline Variable & Number & Percent (\%) \\
\hline Knowledge of pregnancy occurrence on & first sexual & intercourse \\
Yes & 250 & 40 \\
No & 375 & 60 \\
Knowledge of pregnancy prevention methods & \\
Yes & 176 & 28.2 \\
No & 449 & 71.8 \\
Knowledge of pregnancy occurrence dates in relation to menstrual cycle \\
Yes & 122 & 19.5 \\
No & 503 & 80.5 \\
Comprehensive Pregnancy knowledge level & \\
Yes & 75 & 12 \\
No & 550 & 88 \\
\hline
\end{tabular}

One hundred twenty two (19.5\%) of the respondents correctly know menstrual cycle at which a woman has the highest chance to become pregnant. Eighty seven (22.4\%) of males and $14.8 \%$ of females had knowledge of menstrual cycle at which women has the highest chance to become pregnant. Two hundred fifty, (40\%) of the respondents know the possibility of pregnancy occurrence on first sexual intercourse (Table 2).

\subsection{Factors Associated with Comprehensive Pregnancy Knowledge}

Logistic regression analysis shows that, living arrangement was associated with comprehensive pregnancy knowledge, in that, respondents who live with their friends/partners were about three times more likely to have comprehensive pregnancy knowledge compared to those who live with their parents (Adjusted OR[95\% $\mathrm{CI}]=3.1[1.445,6.658]$.

A major source of pregnancy related information was also associated with comprehensive pregnancy knowledge. Respondents who cited health professionals as their major source of pregnancy related information were almost three times more likely to have comprehensive pregnancy knowledge compared to those who cited their parents (Adjusted OR $[95 \% \mathrm{CI}]=2.80[1.16,6.79]$ ).

Table 3. Multivariable logistic regression analysis indicating factors associated with comprehensive pregnancy knowledge among out-of-school youths, Wayu Tuka district, East Wollega zone, Oromia regional state, western Ethiopia, 2014.

\begin{tabular}{|c|c|c|c|c|c|}
\hline \multirow{2}{*}{ Variables } & \multicolumn{5}{|c|}{ Comprehensive pregnancy knowledge level } \\
\hline & Yes & No & Number & $\operatorname{COR}(95 \% \mathrm{CI})$ & AOR(95\%CI) \\
\hline \multicolumn{6}{|l|}{ Sex } \\
\hline Male & 56 & 333 & 389 & 1 & 1 \\
\hline Female & 19 & 217 & 236 & $0.521(0.301,0.90)^{*}$ & $0.60(0.337,1.067)$ \\
\hline \multicolumn{6}{|l|}{ Age } \\
\hline $15-19$ & 24 & 222 & 246 & 1 & 1 \\
\hline $20-24$ & 51 & 328 & 379 & $1.44(0.86,2.40)$ & $1.22(0.678,2.20)$ \\
\hline \multicolumn{6}{|l|}{ Marital status } \\
\hline Un married & 57 & 437 & 494 & 1 & 1 \\
\hline Married & 18 & 113 & 131 & $1.22(0.69,2.157)$ & $0.42(0.179,1.00)$ \\
\hline \multicolumn{6}{|l|}{ Living arrangement } \\
\hline With parents & 40 & 390 & 430 & 1 & 1 \\
\hline With friends and partners & 30 & 134 & 164 & $2.18(1.308,3.644)^{*}$ & $3.1(1.445,6.658)^{*}$ \\
\hline With relatives and others & 5 & 26 & 31 & $1.875(0.682,5.15)$ & $2.19(0.73,6.553)$ \\
\hline \multicolumn{6}{|c|}{ Major sources of information } \\
\hline Parents & 11 & 76 & 87 & 1 & 1 \\
\hline Friends/partners & 15 & 72 & 87 & $1.44(0.62,3.34)$ & $1.63(0.679,3.915)$ \\
\hline Media & 35 & 290 & 325 & $0.83(0.405,1.72)$ & $0.92(0.434,1.953)$ \\
\hline Health professionals & 14 & 35 & 49 & $2.76(1.14,6.699)^{*}$ & $3(1.18,4.608)^{*}$ \\
\hline \multicolumn{6}{|c|}{ Knowledge on STIs other than HIV/AIDS } \\
\hline Yes & 64 & 445 & 509 & $1.37(0.70,2.694)$ & $0.64(0.307,1.326)$ \\
\hline No & 11 & 105 & 116 & 1 & 1 \\
\hline \multicolumn{6}{|c|}{ Having discussion about sexual matter with parents } \\
\hline Yes & 26 & 82 & 108 & $3.03(1.78,5.146)^{*}$ & $2.58(1.46,4.54)^{*}$ \\
\hline No & 49 & 468 & 517 & & 1 \\
\hline \multicolumn{6}{|c|}{ Having current sexual partner } \\
\hline Yes & 61 & 390 & 451 & $1.79(0.97,3.287)$ & $1.196(0.584,2.45)$ \\
\hline No & 14 & 160 & 174 & 1 & 1 \\
\hline \multicolumn{6}{|l|}{ Ever initiated sex } \\
\hline Yes & 33 & 183 & 216 & 1 & 1 \\
\hline No & 42 & 367 & 409 & $0.635(0.39,1.035)$ & $1.05(0.50,2.213)$ \\
\hline
\end{tabular}

N.B: *=Statistically significant association at P-value of $<0.05$.

There was a significant association between comprehensive pregnancy knowledge and sources of pregnancy related knowledge, In that, respondents who got information from health professionals were three times more likely to have comprehensive pregnancy knowledge compared to those who get information from their family members (Adjusted OR[95\%CI] $=3[1.18,4.608]$ ). There was a significant association between having discussion about sexual matter with parents or other family members and comprehensive pregnancy knowledge. Respondents who discussed about sexual matter with their parents or other family members were about two and half times more likely to 
have comprehensive pregnancy knowledge compared to those who were not discussed about sexual matter with their parents or other family members (Adjusted OR $[95 \% \mathrm{CI}]=$ 2.58[1.46,4.54]).

Variables like sex, age, knowledge of sexually transmitted infections, having current sexual partner and ever initiation of sex were not associated with comprehensive pregnancy knowledge (Adjusted OR [95\%CI] $=0.60[0.337,1.067]$, $1.22[0.678,2.20], 0.64[0.307,1.326], 1.196[0.584,2.45]$, $1.05[0.50,2.213]$ respectively) (Table 3 ).

\section{Discussion}

In this study, comprehensive pregnancy knowledge among out of school youths was $12 \%$. Comprehensive pregnancy knowledge was more common among out of school youths who were unmarried, live with their friends/parents, who use health professionals as their major pregnancy related information source and those who discussed about sexual matter with their parents or other family members.

The level of comprehensive pregnancy knowledge among out of school youths in this study was lower than study conducted in eastern Hararge zone (18.5\%) (12). This may be due to the difference in the study subjects since the study in eastern Hararge was conducted on in school adolescents and this study was conducted on out of school youths. In addition to the above reason, the difference in the ways of data collection also makes a difference between the two studies, since this study used interview and the former one used selfadministered questioner.

Living arrangement was associated with comprehensive pregnancy knowledge, in that; respondents who live with their friends/partners were more likely to have comprehensive pregnancy knowledge compared to those who live with their parents. This is supported by study conducted in Ghana (13). The reason may be since youths prefer to communicate freely about sexual matter including pregnancy related knowledge with their friends/partners than their parents.

In this study source of information about pregnancy prevention methods was associated with comprehensive pregnancy knowledge, in that, respondents who cited health professionals as their major source of pregnancy related information were three times more likely to have comprehensive pregnancy knowledge compared to those who cited family members as their pregnancy information source. The reason may be since health professionals provide health related information more openly and supporting with evidences for youths than parents and also parents may not have adequate knowledge to deliver adequate information for their youths.

Having discussion about sexual matter with parents or other family members was significantly associated with comprehensive pregnancy knowledge. Respondents who discussed about sexual matter with their parents or other family members were two and half times more likely to have comprehensive pregnancy knowledge compared to those who were not discussed about sexual matter with their parents or other family members. This is consistence with study conducted in Nekemte town (14), study conducted in Benishangul Gumuz (15) and study conducted in Nepal (16). This may be as a result of those who discussed about sexual matter also discusses about pregnancy prevention than those who consider such like discussion with parents or other family members as a taboo.

\section{Strength and Limitations of the Study}

1. Strength

$\checkmark$ This study had tried to assess comprehensive pregnancy knowledge level among vulnerable out of school youths in rural communities.

2. Limitations

$\checkmark$ Being cross sectional study makes this study difficult to establish temporal relationship.

$\checkmark$ Social desirability bias may be introduced

$\checkmark$ Since there is no enough study on this topic, shortage of reference materials to compare the result.

\section{Conclusions and Recommendations}

About $12 \%$ of respondents had comprehensive pregnancy knowledge. Factors associated with comprehensive pregnancy knowledge includes; marital status, living arrangement, sources of pregnancy related information and having discussion about sexual matter with parents or other family members. Based on the study findings, the following recommendations are forwarded.

District administration and district health office should collaborate each other to intensify pregnancy related IEC that focuses on those who were married, live with their parents, importance of parent-youth communication in communities of the district throughout reach program. District health office should be responsible to establish youth friendly health services at each health institution in the district to attract youths and educate them about sexual and reproductive health including prevention of unwanted pregnancy. Parents and other family members should be encouraged to discuss about sexual matters including pregnancy related issues with their youths through HEWs. Federal ministry of education should be responsible to incorporate sexual and reproductive health to the teaching curriculum at lower classes. In addition, since there is scarcity of studies that assesses comprehensive pregnancy knowledge level of out-of-school and rural youths in Ethiopia, further studies will be needed.

\section{Authors' Contribution}

GK wrote the proposal, participated in data collection, analyzed the data, drafted the paper and revised subsequent drafts of the paper. KT participated in designing of the methodology part. 


\section{Acknowledgement}

Author would like to thanks Haramaya University, College of medical and health sciences, for their financial support to conduct this study. Deep appreciations have gone to Wayu Tuka district administration office, Wayu Tuka district health office and all administrators of the six kebeles of the district which were included in the study. Special thanks to all residents of the selected kebeles, data collectors, supervisors and all peoples who involved in the study directly or indirectly.

\section{References}

[1] WHO. Early marriages, adolescent and young pregnancies Report by the Secretariat Sixty-Fifth World Health Assembly A65/13 Provisional agenda item 2012, 13.4.

[2] National Youth Reproductive Health Strategy (NYRHS). Federal Democratic Republic of Ethiopia Ministry of Health 2006-2015.

[3] UNESCO. World Conference on Higher Education: Paris, the New Dynamics of Higher Education and Research for Societal Change and Development 2009.

[4] Omobuwa O., Asekun-Olarinmoye E. O. And Olajide F. O. Knowledge and perception of reproductive health services among in-school adolescents in Ile-Ife, Osun State, Nigeria. Journal of Medicine and Medical Sciences 2012, 3(7):481-488 Available online http://www.interesjournals.org/JMMS

[5] Cherie A, Berhane Y. Knowledge of Sexually Transmitted Infections and Barriers to Seeking Health Services among High School Adolescents in Addis Ababa, Ethiopia. J AIDS Clinic Res 2012, 3:153.

[6] CSA- [Ethiopia] and ICF International. Ethiopia Demographic and Health Survey 2011. Addis Ababa, Ethiopia and Calverton, Maryland, USA: Central Statistical Agency and ICF International 2012.

[7] IPPF. Facts on American Teens' Sexual and Reproductive Health. Guttmacher Institute 2013.
[8] Shiferaw Y., Alemu A., Girma A., Getahun A., Kassa A., Gashaw A., Alemu A., Teklu T. And Gelaw B. Assessment of knowledge, attitude and risk behaviors towards HIV/AIDS and other sexual transmitted infection among preparatory students of Gondar town, North West Ethiopia. BMC Research Notes 2011, 4:505

[9] Awala E. Adolescent Sexual and Reproductive Health Service Utilization in Tigray, Ethiopia Relief Society of Tigray 2005.

[10] Alemayehu S., Mesganaw F., Alemayehu W. Reproductive health needs of out-of-school adolescents: A cross-sectional comparative study of rural and urban areas in northwest Ethiopia, Ethiop .J. Health Dev 2006, 20(1)

[11] Wayu tuka district Agriculture and rural development office report, 2006-2007.

[12] Oljira L., Berhane Y., and Worku A. Assessment of comprehensive HIV/AIDS knowledge level among in-school adolescents in eastern Ethiopia. Journal of the International AIDS Society 2013, 16:17349

[13] Agyemang S., Buor D. And Tagoe-Darko E. The extent of knowledge about HIV/AIDS among young people in the Ejura-Sekyedumase district of Ghana. Journal of AIDS and HIV Research 2012, 4(11): 241-247.

[14] Tesso W., Fantahun A. And Fikire E. Parent-young people communication about sexual and reproductive health in E/Wollega zone, West Ethiopia: Implications for interventions. Reproductive Health 2012, 9:13

[15] Desalegn G., Mesganaw F. Assessing communication on sexual and reproductive health issues among high school students with their parents, Bullen Woreda, Benishangul Gumuz Region of North West Ethiopia. Ethiopian. J. Health Dev. 2010, 24(2)

[16] Padam P. Simkhada, Edwin R. van Teijlingen, Dev Raj Acharya, Eva Schildbach, Pushkar Raj Silwal, Jamuna Shrestha, PushpaLataPandey. Sexual and Reproductive Health of Adolescents in Rural Nepal: Knowledge, Attitudes and Behavior, Nepal Population Journal2012, 17(16) 